\title{
PENGGUNAAN SITUS WEB HOTEL DAN “ONLINE TRAVEL AGENCY" SEBAGAI MEDIA PROMOSI DAN PENJUALAN BAGI HOTEL MELATI DI UBUD
}

\author{
Pande Putu Indrayana Tirtayasa \\ Prodi Magister Kajian Pariwisata Universitas Udayana \\ Email: indrayana@tirtayasa.com \\ Syamsul Alam Paturusi \\ Prodi Magister Kajian Pariwisata Universitas Udayana \\ syamsul_alam_paturusi@yahoo.fr
}

\begin{abstract}
The growth of the number of hotel rooms in Ubud has caused increasing business competition among the so called non-star melati hotel. Non-star melati hotel is a category of hotel which is not qualified to be awarded as a star hotel by Indonesian Ministry of Tourism. In response to the competition, the hotels embrace internet as a sales and promotion media by developing hotel websites. Individual tourism trend ignites the emergence of online travel agency websites (OTA) which used by tourists to compare and choose hotels thus increasing the importance of internet as a channel for selling and promoting hotel products. The purposes of this research are to identify motivation, perception, advantages and disadvantages of hotel website and OTA by non-star melati hotel operator's perspective. Theories used are motivation, perception, and SWOT theory. Data was analyzed with descriptive qualitative method. Results show that hotel website and OTA have its own advantages and disadvantages. Motivation in using hotel website and OTA are very high. Perception in using hotel website and OTA are very agree. It is advised that hotels need to focus more on using OTA as source of getting guests, but also using hotel website, together as medium for promotion and sales activities.
\end{abstract}

Keywords: Non-star melati hotel, Ubud, hotel website, online travel agency

\section{Pendahuluan}

Usaha hotel melati di Kecamatan Ubud berkembang positif dalam rentang tahun 2010 hingga 2014. Perkembangan usaha hotel melati terlihat dari pertumbuhan jumlah kamar hotel melati yang terus mengalami peningkatan tiap tahunnya. Jumlah kamar hotel melati yang terus 
meningkat mengakibatkan peningkatan persaingan di antara usaha hotel melati. Persaingan ini mendorong pengelola hotel melati untuk lebih intensif melakukan kegiatan promosi agar hotel mereka lebih dikenal oleh wisatawan.

Internet sebagai media komunikasi dan pencarian informasi telah umum digunakan di seluruh dunia. Di bidang pariwisata, internet menjadi tempat pencarian informasi bagi wisatawan yang berencana untuk melakukan kegiatan berwisata, baik itu informasi tentang daerah yang akan dikunjungi, tempat-tempat menarik yang ada di sana, maupun tempat-tempat menginap dan harganya. Google (2014) menyatakan bahwa 65\% wisatawan leisure dan $67 \%$ wisatawan bisnis mencari informasi di internet terlebih dahulu untuk mencari tahu segala informasi tentang suatu tempat yang akan dikunjungi seperti tempat wisata yang berada di tempat tersebut, moda transportasi untuk kesana, tempat makan, tempat menginap, dan sebagainya. Banyaknya wisatawan yang menggunakan internet dilihat oleh pengelola hotel sebagai peluang untuk menjadikannya channel promosi yang ditindak lanjuti dengan hadir di internet dalam bentuk web hotel.

Internet memberikan penghematan bagi pengelola hotel melati dalam hal biaya kegiatan promosi, karena material promosi yang sebelumnya harus dicetak dan disebarkan melalui pos atau kurir sekarang bisa berbentuk digital dan dikirimkan melalui email atau disediakan di web hotel agar diunduh sehingga distribusi material promosi dilakukan secara cepat dibandingkan dengan cara offline. Web hotel selain sebagai media promosi juga digunakan sebagai media untuk berjualan dengan penambahan fitur penjualan kamar otomatis dalam web hotel. Wisatawan yang memutuskan untuk menginap bisa memesan kamar di web hotel dengan memilih tanggal check in dan check out, kemudian melihat jenis dan harga kamar yang tersedia pada tanggal tersebut. Setelah memutuskan untuk memilih jenis kamar yang tersedia, akan dilanjutkan ke pengisian metode pembayaran, yang umumnya adalah memakai kartu kredit. Jika web hotel tidak memiliki fitur penjualan kamar otomatis, wisatawan bisa melakukan request melalui email kepada pengelola hotel yang tertera dalam web hotel.

Banyaknya pilihan web hotel di internet yang harus dilihat oleh wisatawan dalam memilih tempat menginap mendorong kemunculan situs-situs web berjenis online travel agency (OTA) dimana di dalamnya usaha hotel yang berada dalam suatu lokasi dikelompokkan dalam satu kategori sehingga memudahkan dalam memilih. Dalam situs web jenis ini wisatawan diberikan fasilitas untuk (1) melihat usaha-usaha hotel yang terdapat di Ubud atau daerah tujuan wisata lainnya, (2) membandingkan harga dan fasilitas masing-masing usaha hotel serta melihat review tamu mereka, dan (3) booking kamar langsung di situs web tersebut. OTA disini memiliki fungsi yang sama dengan web hotel, yaitu sebagai tempat berpromosi dan berjualan. Berbagai 
kemudahan tersebut membuat OTA disukai oleh wisatawan sebagai tempat untuk booking kamar hotel. Google (2014) menyatakan bahwa secara global OTA populer sebagai sumber pencarian informasi untuk pemilihan usaha hotel saat travel planning di samping web hotel resmi dan popularitasnya akan terus meningkat. Kemunculan OTA disikapi oleh pengelola usaha hotel melati dengan mendaftarkan dirinya dalam OTA dan menjadikannya sebagai media promosi dan penjualan di internet disamping tetap menjalankan web hotel yang mereka miliki. OTA yang berasal dari luar negeri antara lain Agoda.com, Booking.com, Expedia.com, Hotels.com, Kayak.com, Orbitz.com, Priceline.com, Travelocity.com, dan Wotif.com, serta OTA dari dalam negeri seperti Goindonesia.com, Nusatrip.com, Pegipegi.com, Rajakamar.com, Tiket.com, dan Traveloka.com. Untuk masuk mendaftar dan berjualan dalam OTA tidak dikenakan biaya, tetapi OTA akan memungut komisi pada setiap transaksi penjualan kamar. Besarnya komisi umumnya sebesar 15\%, tetapi usaha hotel bisa memberikan komisi lebih besar dengan benefit pemasangan iklan dalam OTA dan search engine seperti Google, Bing, dan Yahoo. Usaha hotel yang berjualan dalam OTA diistilahkan sebagai hotel partners.

Untuk menjadi hotel partners, pengelola hotel harus melakukan signup (registrasi) secara online di situs web OTA (contohnya di Booking.com adalah https://join.booking.com). Untuk registrasi dan berlangganan dalam OTA tidak dikenakan biaya. Data-data yang harus dimasukkan pada halaman web registrasi adalah (1) tipe hotel (homestay, vila, hotel, motel, dan sebagainya), (2) nama hotel, (3) nama pengelola, (4) alamat email pengelola. Setelah data tersebut dikirim, halaman web akan beralih ke property details, dimana dalam halaman web ini pengelola harus memasukkan deskripsi dari hotel dan kamar, foto-foto, dan payment policy. Di halaman web ini pengelola hotel menentukan besaran komisi yang ingin diberikan kepada OTA dengan memilih berdasarkan opsi yang tersedia. Setelah semua data property details dikirim selanjutnya akan diperiksa oleh pihak OTA untuk menghindari duplikasi dengan hotel lain yang sebelumnya telah terdaftar dalam OTA. Jika OTA mengkonfirmasi, selanjutnya hotel akan tampil dan bisa mulai berjualan.

Tingkat penggunaan teknologi internet dalam bentuk web hotel oleh usaha hotel melati di Ubud adalah tinggi, dimana dari 119 usaha hotel melati terdapat 107 yang memiliki web hotel. Sebagian besar dari web hotel tersebut digunakan sebagai media penjualan kamar dengan cara korespondensi antara wisatawan dengan pengelola hotel, sebanyak 40 web hotel memiliki fasilitas booking otomatis. Ada 12 hotel yang tidak memiliki web hotel dimana sebagian besar beralasan tidak memiliki orang untuk mengurusnya. Penggunaan teknologi internet dalam bentuk OTA oleh usaha hotel melati di Kecamatan Ubud adalah tinggi, dimana dari 119 usaha hotel melati semuanya ditemukan memiliki kehadiran di OTA. 


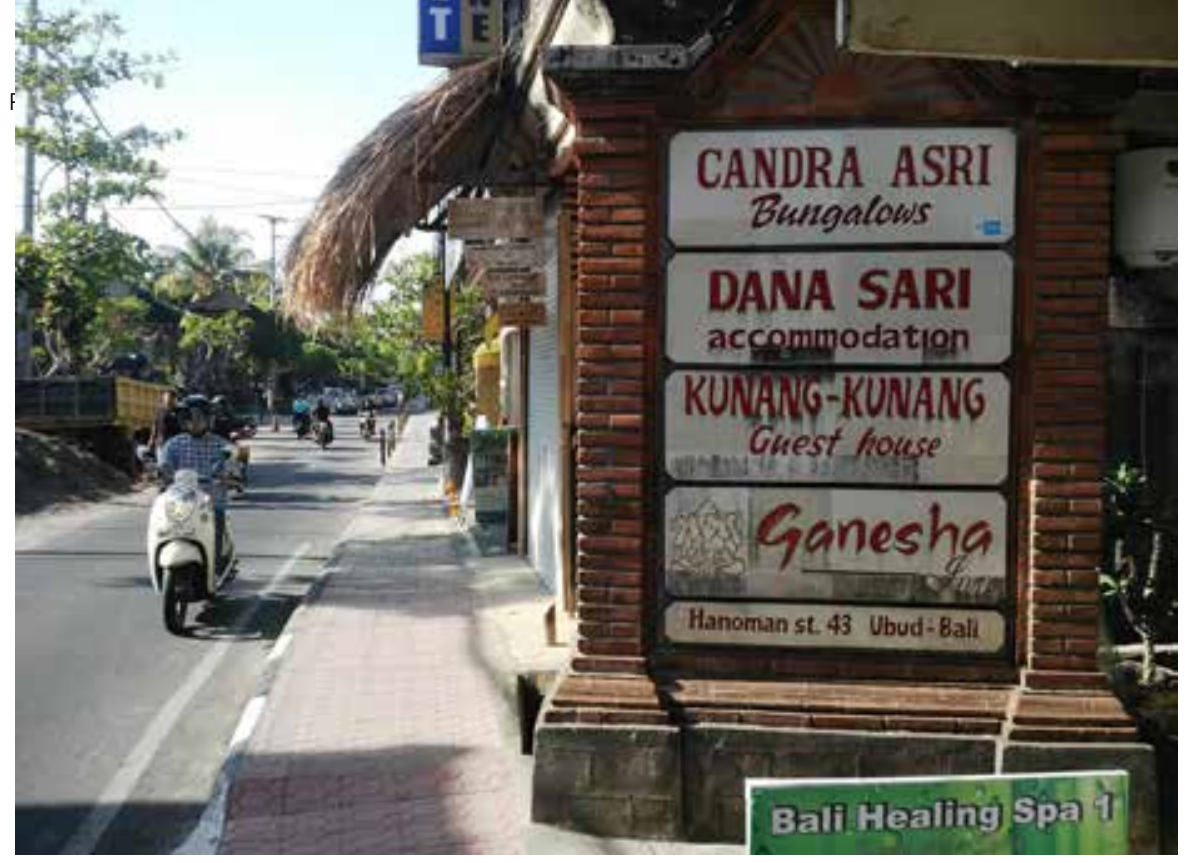

PANDE PUTU INDRAYANA TIRTAYASA

Foto 1. Beberapa usaha hotel melati di Ubud yang menggunakan web hotel dan OTA sebagai media promosi dan penjualan.

Kemajuan teknologi informasi serta persaingan yang ketat mendorong penggunaan internet sebagai media promosi dan penjualan bagi usaha hotel melati di Kecamatan Ubud. Perkembangan trend wisata dari wisata massal ke wisata individual mendorong lebih jauh lagi penggunaan internet untuk mendapatkan tamu. Web hotel dan OTA menjadi channel untuk berpromosi dan berjualan di trend yang baru ini. Oleh sebab itu maka perlu suatu penelitian yang bertujuan untuk mengetahui (1) kekurangan dan kelebihan, (2) motivasi, serta (3) persepsi pengelola hotel melati di Kecamatan Ubud terhadap penggunaan web hotel dan OTA sebagai media promosi dan penjualan.

\section{Teori dan Metode}

Teori yang digunakan dalam penelitian ini adalah teori SWOT, teori motivasi, dan teori persepsi. Robinson (1997) menyatakan bahwa analisis SWOT merupakan cara sistematik untuk mengidentifikasi berbagai faktor dan menggambarkan kecocokan paling baik di antara faktor tersebut. Ditambahkan oleh Rangkuti (2001) bahwa analisis ini didasarkan pada logika untuk dapat memaksimalkan kekuatan (strengths) dan peluang (opportunities), namun secara bersamaan dapat meminimalkan kelemahan (weaknesses) dan ancaman (threats).

Motivasi merupakan segala sesuatu yang mendorong seseorang untuk bertindak melakukan sesuatu. Purwanto (2013) menjelaskan bahwa motivasi merupakan suatu usaha yang disadari dan memengaruhi tingkah laku agar tergerak hatinya untuk bertindak melakukan sesuatu sehingga mencapai 
hasil atau tujuan tertentu, sehingga seseorang melakukan sesuatu karena adanya kebutuhan di dalam dirinya atau ada sesuatu yang hendak dicapai.

Teori motivasi Mc. Guire menyebutkan bahwa ada dua jenis motivasi berdasarkan dari faktor pembentuknya, yaitu: motivasi internal dan motivasi eksternal (Neal dkk., 2004). Motivasi internal disebabkan karena kebutuhan dalam diri seseorang. Motivasi eksternal disebabkan karena kebutuhan di luar diri seseorang. Motivasi internal didorong oleh enam hal yaitu (1) kebutuhan akan konsistensi, (2) kebutuhan akan pencapaian prestasi, (3) kebutuhan akan tanggung jawab, (4) kebutuhan akan atribut penyebab, (5) kebutuhan akan kontrol pribadi, dan (6) kebutuhan akan sesuatu yang baru. Motivasi eksternal didorong oleh empat hal yaitu (1) kebutuhan akan afiliasi, (2) kebutuhan akan upah, (3) kebutuhan akan kemudahan, dan (4) kebutuhan untuk meniru.

Persepsi merupakan suatu proses yang didahului oleh penginderaan, yaitu proses berwujud diterimanya rangsangan oleh individu melalui alat inderanya. Namun, proses ini tidak berhenti sampai di situ melainkan rangsangan itu diteruskan ke pusat susunan saraf yaitu otak dan terjadilah proses psikologi sehingga individu menyadari akan apa yang dilihat, apa yang didengar, dan sebagainya (Walgito, 1990). Winardi (2011) menyatakan bahwa persepsi merupakan sebuah proses yang bersifat otomatis dan bekerja dengan cara yang hampir serupa pada setiap individu. Persepsi seseorang tentang situasi tertentu atau pesan tertentu menjadi landasan berdasarkan apa ia berprilaku.

Teori persepsi menjelaskan bahwa ada faktor-faktor yang mempengaruhi persepsi yaitu terletak (a) pada diri pembentuk persepsi, (b) dalam diri objek atau target yang diartikan, dan (c) dalam konteks situasi dimana persepsi itu dibuat (Robbins dan Judge, 2008). Karakteristik pribadi yang memengaruhi persepsi meliputi: sikap, kepribadian, motivasi, minat, pengalaman masa lalu, dan harapan-harapan seseorang. Karakteristik target yang diobservasi yang diartikan seperti: sesuatu yang baru, tampilan (suara, ukuran, latar belakang), kedekatan dan kemiripan. Karakteristik situasional yaitu: waktu, keadaan kerja, keadaan sosial.

Penelitian ini dilakukan di Kecamatan Ubud, Kabupaten Gianyar dengan teknik pengumpulan data observasi, angket, dan wawancara. Populasi dalam penelitian ini adalah pengelola hotel melati yang menangani kegiatan promosi dan penjualan dengan jabatan mulai dari staf, supervisor, manager, director, hingga owner representative, dimana populasi usaha hotel melati di Ubud adalah 119 hotel. Sampel sebagai responden pengisi kuesioner adalah 54 responden yang dibagi berdasarkan teknik cluster proportional sampling dengan rincian 36 dari Kelurahan Ubud, satu dari Desa Singakerta, dua dari Desa Sayan, tujuh dari Desa Kedewatan, satu dari Desa Lodtunduh, dua dari Desa Mas, tiga dari Desa Peliatan, dan dua dari Desa Petulu. Lima 
orang informan untuk wawancara ditentukan berdasarkan teknik purposive sampling. Analisis data menggunakan analisis data deskriptif kualitatif.

\section{Kelebihan dan Kekurangan Web Hotel dan OTA}

Untuk mengetahui kelebihan dan kekurangan melakukan promosi dan penjualan melalui web hotel dan OTA, dilakukan wawancara mendalam dengan lima orang informan pengelola hotel melati di Kecamatan Ubud yang terdiri dari Wahyu Suteja Managing Director dari Komaneka, Ketut Suabawa Owner Representative dari Anhera, Budi Susanta General Manager dari Ubud Village, Luh Sukarini General Manager dari Ubud Green, serta Gede Nusantara Sales Manager dari Wapa Di Ume. Wawancara mendalam dilakukan melalui pertemuan secara langsung dan korespondensi melalui email. Dari wawancara terungkap bahwa web hotel dan OTA memiliki kelebihan dan kekurangannya masing-masing. Kelebihan yang dimaksud dalam penelitian ini adalah kekuatan dan peluang (strengths and opportunities), sedangkan kekurangan yang dimaksud adalah kelemahan dan ancaman (weaknesses and threats).

Adapun kekuatan dari web hotel adalah: (a) web hotel adalah representasi resmi dari hotel di dunia maya, (b) desain web hotel sepenuhnya dikendalikan oleh pengelola hotel, (c) web hotel menghemat biaya produksi dan distribusi material promosi, (d) berjualan di web hotel mendapatkan margin profit yang lebih tinggi karena tidak adanya pemotongan komisi pihak ketiga, dan (e) web hotel dimungkinkan untuk promosi dan berjualan hal-hal tambahan yang berkaitan dengan penjualan kamar. Peluang dari web hotel adalah: (a) tumbuhnya pariwisata individual, (b) pembuatan situs web semakin mudah, dan (c) biaya operasional web hotel perbulan yang murah. Satu kelemahan web hotel adalah terbuka untuk dilihat semua orang termasuk kompetitor sehingga program promosi yang ditampilkan di web hotel berpeluang untuk diketahui dan ditiru oleh kompetitor. Satu ancaman web hotel adalah usaha hotel melati di Kecamatan Ubud yang terus bertambah.

Salah satu kekuatan web hotel yaitu desain yang sepenuhnya dikendalikan oleh pengelola hotel akan berpengaruh kepada citra hotel bagaimana yang ingin ditunjukkan kepada wisatawan, seperti diutarakan oleh Wahyu Suteja:

"Desain situs web hotel mencerminkan kelas dari hotel tersebut. Desain yang indah dipandang tentu akan menimbulkan kesan baik bagi wisatawan dan menarik minat untuk membuka-buka lebih dalam situs web hotel tersebut serta memancarkan citra bahwa hotel tersebut adalah hotel yang berkelas” (Wawancara, 21 Oktober 2015).

Citra hotel yang terlihat dari web hotel tentunya akan berpengaruh dalam penjualan. Web hotel yang menarik untuk dilihat akan menjadi salah satu faktor yang mendorong wisatawan untuk melihat-lihat isi web hotel lebih 
dalam sehingga memperbesar peluang untuk terjadinya penjualan kamar.

Kekuatan dari OTA adalah: (a) Pengelola hotel tidak dikenakan biaya untuk mendaftar masuk di dalamnya, dan (b) pembayaran booking dibayarkan langsung oleh OTA kepada hotel. Satu peluang OTA yaitu bahwa OTA adalah media yang semakin populer bagi wisatawan untuk mencari informasi saat perencaan kegiatan berwisata. Kelemahan OTA adalah: (a) Penjualan bersih yang diterima pengelola hotel berkurang karena harus membayar komisi OTA, dan (b) OTA tidak menampilkan link web hotel di halaman hotel dalam OTA. Satu ancaman OTA adalah bahwa jumlah OTA yang semakin bertambah.

Pemakaian internet sebagai media untuk promosi dan penjualan meskipun memiliki keunggulan tetapi tidak bisa sepenuhnya menggantikan kegiatan promosi dan penjualan konvensional di antaranya seperti kerja sama dengan travel agency dan penempatan brosur di tempat-tempat strategis seperti tourist information center, seperti dikatakan oleh Ketut Suabawa:

"Internet adalah salah satu media yang kita gunakan jualan, baik itu website atau OTA. Selain internet online itu, yang offline juga tetap kita maintain. Intinya adalah bagaimana memiliki channel sebanyak-banyaknya" (Wawancara 24 Oktober 2015).

Web hotel dan OTA digunakan oleh usaha hotel sebagai channel penjualan yang digunakan bersama-sama dengan channel penjualan lainnya agar tercapai tingkat hunian kamar semaksimal mungkin. Hal ini juga untuk menghindari ketergantungan terhadap satu channel tertentu, sehingga jika production dari suatu channel penjualan menurun maka diharapkan akan ada backup dari channel yang lainnya.

\section{Motivasi penggunaan web hotel dan OTA}

Hasil penelitian dari 54 responden pengelola hotel melati di Kecamatan Ubud digunakan untuk mengetahui motivasi dan persepsi penggunaan web hotel dan OTA. Motivasi pengelola hotel melati dalam menggunakan web hotel secara umum adalah sangat tinggi dengan nilai rata-rata 4,20. Pengelola hotel melati termotivasi secara internal dan eksternal dimana skor rata-rata motivasi internal lebih besar dibandingkan dengan motivasi eksternal dengan nilai 4,42 berbanding 3,88 seperti terlihat dalam Tabel 1.

Dari keseluruhan faktor motivasi, yang memiliki skor rata-rata tertinggi adalah faktor motivasi internal dengan indikator kebutuhan akan kontrol pribadi. Hal ini menunjukkan bahwa yang paling mendorong pengelola hotel melati di Ubud untuk menggunakan web hotel adalah keleluasaan untuk mengatur aspek-aspek yang ada dalam web hotel seperti desain, foto, teks, dan sebagainya. 
Tabel 1. Motivasi Pengelola Hotel Melati terhadap Penggunaan Web Hotel

\begin{tabular}{clcl}
\hline Faktor & \multicolumn{1}{c}{ Indikator } & Skor Rata-rata & Tingkat Motivasi \\
\hline & 1. Kebutuhan akan konsistensi & 4,61 & Sangat Tinggi \\
Motivasi & 2. Kebutuhan akan pencapaian prestasi & 4,17 & Tinggi \\
Internal Kebutuhan akan tanggung jawab & 4,17 & Tinggi \\
& 4. Kebutuhan akan atribut penyebab & 4,83 & Sangat Tinggi \\
& 5. Kebutuhan akan kontrol pribadi & 4,89 & Sangat Tinggi \\
& 6. Kebutuhan akan sesuatu yang baru & 3,83 & Tinggi \\
& $\quad$ Rata-rata Motivasi Internal & 4,42 & Sangat Tinggi \\
Motivasi & 1. Kebutuhan akan afiliasi & 3,44 & Tinggi \\
2. Kebutuhan akan upah & 3,44 & Tinggi \\
& 3. Kebutuhan akan kemudahan & 4,56 & Sangat Tinggi \\
& 4. Kebutuhan untuk meniru & 4,06 & Tinggi \\
& Rata-rata Motivasi Eksternal & 3,88 & Tinggi \\
& Rata-rata Umum & 4,20 & Sangat Tinggi \\
\hline
\end{tabular}

Sumber: Diolah oleh peneliti.

Motivasi pengelola hotel melati dalam menggunakan OTA secara umum adalah sangat tinggi dengan nilai rata-rata 4,25. Pengelola hotel melati termotivasi secara internal dan eksternal dimana skor rata-rata motivasi internal lebih besar dibandingkan dengan motivasi eksternal dengan nilai 4,42 berbanding 4,oo seperti terlihat dalam Tabel 2.

Tabel 2. Motivasi Pengelola Hotel Melati terhadap Penggunaan OTA

\begin{tabular}{clcl}
\hline Faktor & \multicolumn{1}{c}{ Indikator } & Skor Rata-rata & Tingkat Motivasi \\
\hline & 1. Kebutuhan akan konsistensi & 4,52 & Sangat Tinggi \\
Motivasi & 2. Kebutuhan akan pencapaian prestasi & 4,17 & Tinggi \\
Internal & 3. Kebutuhan akan tanggung jawab & 4,24 & Sangat Tinggi \\
& 4. Kebutuhan akan atribut penyebab & 4,83 & Sangat Tinggi \\
& 5. Kebutuhan akan kontrol pribadi & 4,89 & Sangat Tinggi \\
& 6. Kebutuhan akan sesuatu yang baru & 3,85 & Tinggi \\
& Rata-rata motivasi internal & 4,42 & Sangat Tinggi \\
Motivasi Ek- & 1. Kebutuhan akan afiliasi & 3,59 & Tinggi \\
sternal & 3. Kebutuhan akan upah & 3,52 & Tinggi \\
& 4. Kebutuhan akan kemudahan & 4,65 & Sangat Tinggi \\
\hline & Rata-rata motivasi eksternal & 4,24 & Sangat Tinggi \\
\hline & Rata-rata umum & 4,00 & Tinggi \\
\hline
\end{tabular}

Sumber: Diolah oleh peneliti.

Dari keseluruhan faktor motivasi, yang memiliki skor rata-rata tertinggi adalah faktor motivasi internal dengan indikator kebutuhan akan kontrol pribadi. Hal ini menunjukkan bahwa yang paling mendorong pengelola hotel melati di Kecamatan Ubud menggunakan OTA adalah keleluasaan untuk mengatur aspek-aspek yang ada dalam OTA di antaranya adalah harga kamar.

\section{Persepsi penggunaan web hotel dan OTA}

Persepsi pengelola hotel melati terhadap web hotel sebagai media promosi dan penjualan secara umum adalah sangat setuju dengan nilai rata- 
rata 4,44. Nilai rata-rata faktor persepsi tertinggi adalah faktor situasional dengan nilai 4,49, lalu faktor persepsi dari dalam diri pengelola hotel melati dengan nilai 4,43, lalu faktor persepsi dalam diri target (web hotel) dengan nilai 4,41 seperti terlihat dalam Tabel 3 .

Tabel 3. Persepsi Pengelola Hotel Melati terhadap Penggunaan Web Hotel

\begin{tabular}{|c|c|c|c|}
\hline Faktor & Indikator & Skor Rata-rata & Tingkat Persepsi \\
\hline \multirow{5}{*}{$\begin{array}{l}\text { Faktor dalam diri } \\
\text { si pengarti } \\
\text { (pengelola hotel } \\
\text { melati) }\end{array}$} & 1. Sikap & 4,89 & Sangat Setuju \\
\hline & 2. Motif & 4,81 & Sangat Setuju \\
\hline & 3. Minat & 4,20 & Sangat Setuju \\
\hline & 4. Pengalaman & 4,19 & Setuju \\
\hline & 5. Harapan & 4,06 & Setuju \\
\hline \multirow{7}{*}{$\begin{array}{l}\text { Faktor dalam } \\
\text { diri target } \\
\text { (web hotel) }\end{array}$} & Rata-rata Faktor dalam diri pengarti & 4,43 & Sangat Setuju \\
\hline & 1. Sesuatu yang baru & 4,54 & Sangat Setuju \\
\hline & 2. Persepsi tampilan depan & 4,89 & Sangat Setuju \\
\hline & 3. Latar belakang & 4,70 & Sangat Setuju \\
\hline & 4. Kerja sama & 3,87 & Setuju \\
\hline & 5. Kemiripan tata cara penggunaan & 4,04 & Setuju \\
\hline & Rata-rata faktor dalam diri target & 4,41 & Sangat Setuju \\
\hline \multirow{5}{*}{$\begin{array}{l}\text { Faktor } \\
\text { situasional }\end{array}$} & 1. Waktu & 4,02 & Setuju \\
\hline & 2. Keadaan kerja & 4,70 & Sangat Setuju \\
\hline & 3. Keadaan sosial & 4,76 & Sangat Setuju \\
\hline & Rata-rata faktor situasional & 4,49 & Sangat Setuju \\
\hline & Rata-rata umum & 4,44 & Sangat Setuju \\
\hline
\end{tabular}

Sumber: Diolah oleh peneliti.

Dari keseluruhan faktor persepsi, yang memiliki skor rata-rata tertinggi adalah faktor dalam diri si pengarti dengan indikator sikap. Hal ini menunjukkan bahwa tingkat persepsi tertinggi adalah sikap atau pendapat pengelola hotel melati atas web hotel adalah sebagai media promosi dan penjualan yang penting untuk digunakan.

Persepsi pengelola hotel melati terhadap OTA sebagai media promosi dan penjualan secara umum adalah sangat setuju dengan nilai rata-rata 4,51. Nilai rata-rata faktor persepsi tertinggi adalah faktor persepsi dari dalam diri pengelola hotel melati dengan nilai 4,56, lalu faktor persepsi situasional dengan nilai rata-rata 4,49, lalu faktor persepsi dalam diri target (OTA) dengan nilai 4,46 seperti terlihat dalam Tabel 4 .

Dari keseluruhan faktor persepsi, yang memiliki skor rata-rata tertinggi adalah faktor dalam diri si pengarti dengan indikator sikap. Hal ini menunjukkan bahwa pengelola hotel melati melihat bahwa OTA adalah suatu hal yang penting digunakan untuk promosi dan penjualan.

\section{Simpulan dan Saran}

Berdasarkan uraian di atas dapat ditarik kesimpulan, pertama, web hotel serta OTA sebagai media promosi dan penjualan di internet dirasakan memberikan manfaat oleh pengelola hotel melati di Kecamatan Ubud. 


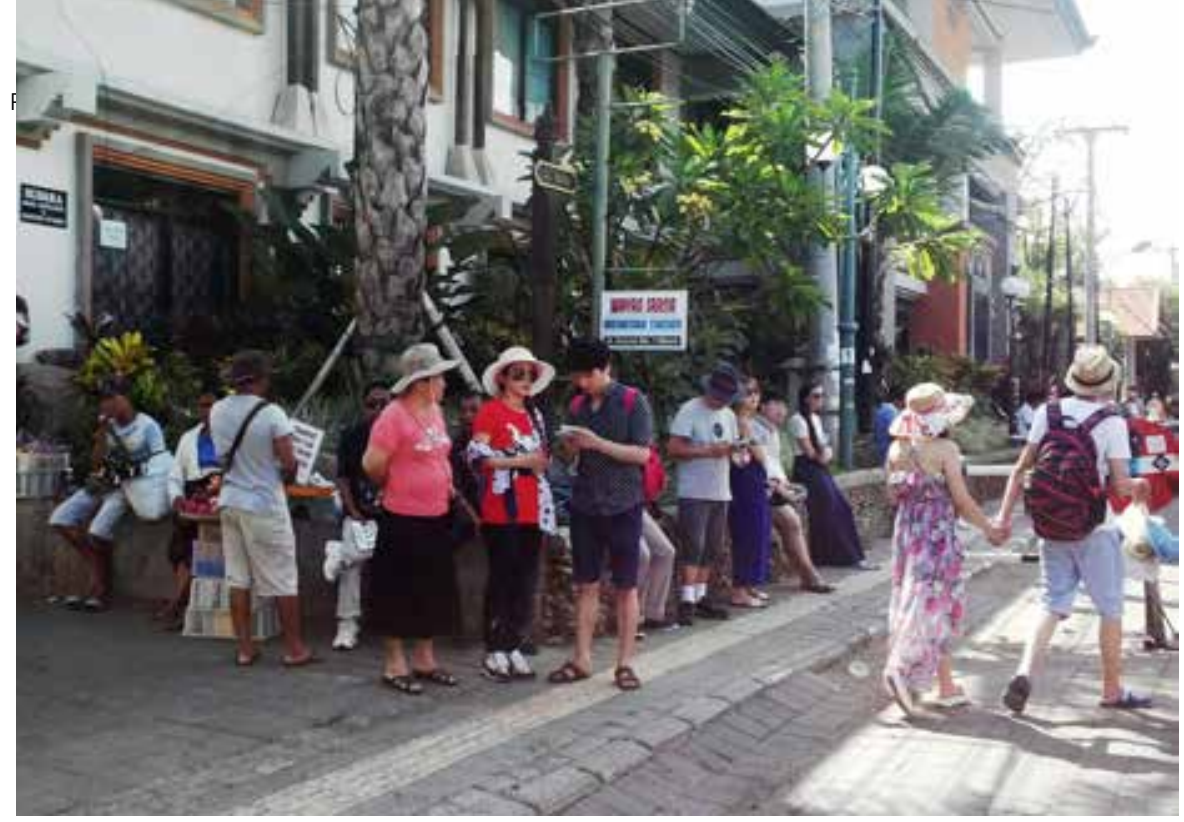

Foto 2. Aktivitas wisatawan di Jalan Raya Ubud (Sumber: dokumentasi penulis).

Tabel 4. Persepsi Pengelola Hotel Melati terhadap Penggunaan OTA

\begin{tabular}{|c|c|c|c|}
\hline \multirow[b]{2}{*}{\begin{tabular}{l}
\multicolumn{1}{c}{ Faktor } \\
Faktor dalam diri \\
si pengarti \\
(pengelola hotel \\
melati)
\end{tabular}} & Indikator & \multicolumn{2}{|c|}{ Skor Rata-rata Tingkat Persepsi } \\
\hline & $\begin{array}{l}\text { 1. Sikap-sikap } \\
\text { 2. Motif-motif } \\
\text { 3. Minat-minat } \\
\text { 4. Pengalaman } \\
\text { 5. Harapan-harapan }\end{array}$ & $\begin{array}{l}4,89 \\
4,81 \\
4,20 \\
4,85 \\
4,06 \\
\end{array}$ & $\begin{array}{l}\text { Sangat Setuju } \\
\text { Sangat Setuju } \\
\text { Sangat Setuju } \\
\text { Sangat Setuju } \\
\text { Setuju }\end{array}$ \\
\hline \multicolumn{2}{|c|}{ Rata-rata faktor dalam diri pengarti } & 4,56 & Sangat Setuju \\
\hline $\begin{array}{l}\text { Faktor dalam } \\
\text { diri target } \\
\text { (OTA) }\end{array}$ & $\begin{array}{l}\text { 1. Sesuatu yang baru } \\
\text { 2. Persepsi tampilan depan } \\
\text { 3. Latar belakang } \\
\text { 4. Kerja sama } \\
\text { 5. Kemiripan tata cara penggunaan }\end{array}$ & $\begin{array}{l}4,54 \\
4,89 \\
4,70 \\
4,11 \\
4,04\end{array}$ & $\begin{array}{l}\text { Sangat Setuju } \\
\text { Sangat Setuju } \\
\text { Sangat Setuju } \\
\text { Setuju } \\
\text { Setuju }\end{array}$ \\
\hline \multicolumn{2}{|c|}{ Rata-rata faktor dalam diri target } & 4,46 & Sangat Setuju \\
\hline Faktor situasional & $\begin{array}{l}\text { 1. Waktu } \\
\text { 2. Keadaan kerja } \\
\text { 3. Keadaan sosial }\end{array}$ & $\begin{array}{l}4,02 \\
4,70 \\
4,76\end{array}$ & $\begin{array}{l}\text { Setuju } \\
\text { Sangat Setuju } \\
\text { Sangat Setuju }\end{array}$ \\
\hline \multicolumn{2}{|r|}{ Rata-rata faktor situasional } & 4,49 & Sangat Setuju \\
\hline & Rata-rata umum & 4,51 & Sangat Setuju \\
\hline
\end{tabular}

Sumber: Diolah oleh peneliti.

Kedua media ini berperan dalam kontribusi peningkatan tingkat hunian kamar hotel melati di Ubud, tetapi sama-sama memiliki kelebihan dan kekurangannya masing-masing.

Kedua, secara umum motivasi pengelola hotel melati di Kecamatan Ubud terhadap penggunaan web hotel dan OTA adalah sangat tinggi. Dimana faktor pendorong motivasi dengan skor rata-rata tertinggi adalah faktor internal dengan indikator kontrol pribadi. Kontrol pribadi adalah faktor pendorong motivasi dimana pengelola hotel memiliki kendali atas apa yang ditampilkan di web hotel dan OTA serta jika diperlukan perubahan atau 
pembaharuan atas apa yang ditampilkan maka pengelola hotel bisa langsung mengerjakannya.

Ketiga, persepsi pengelola hotel melati di Kecamatan Ubud terhadap penggunaan web hotel dan OTA secara umum adalah sangat setuju, dengan faktor tertinggi adalah faktor dalam diri pengarti indikator sikap. Sikap adalah pendapat pengelola hotel yang sangat setuju terhadap penggunaan web hotel dan OTA adalah sebagai media untuk berpromosi dan penjualan yang bertujuan untuk meningkatkan tingkat hunian kamar.

Saran dari penelitian ini adalah, pertama, perlu dilakukan penelitian lebih lanjut tentang penggunaan media lain di internet seperti Facebook, Twitter, Instagram dan lainnya untuk mengetahui kelebihan, kekurangan, atau efektivitas media online tersebut untuk promosi dan penjualan. Kedua, pengelola hotel, khususnya hotel baru, disarankan untuk memberi perhatian lebih untuk menggunakan OTA dalam kegiatan berjualan kamar hotel karena berpeluang untuk lebih cepat mendapatkan tamu. Ketiga, pengelola hotel harus mempertimbangkan untuk menambahkan fungsi penjualan otomatis agar web hotel lebih menarik dan menjadi channel tambahan untuk berjualan di internet selain OTA.

\section{Ucapan Terima Kasih}

Penulis menyampaikan ucapan terima kasih kepada Prof. Dr. I Nyoman Darma Putra, M.Litt dan Dr. Ir. Syamsul Alam Paturusi, MSP sebagai Pembimbing I dan Pembimbing II dalam riset penulisan tesis saat menempuh pendidikan di Prodi S2 Kajian Pariwisata Universitas Udayana. Prof. Made Sudiana Mahendra, Ph.D, Prof. Dr. Ir. Made Antara, MS, dan Dr. I Nyoman Madiun, M.Sc selaku penguji yang juga memberikan masukan, saran, dan koreksi. Ucapan terima kasih juga penulis sampaikan kepada seluruh pihak yang telah membantu sehingga penelitian ini terlaksana.

\section{Daftar Pustaka}

Google. 2014. The 2014 Traveler's Road to Decision, [cited 2015 Des. 20]. Available from: thinkwithgoogle.com/research-studies/2014-travelers-road-to-decision. html

Neal, Cathy, Pascale Quester dan Del I. Hawkins. 2004. Consumer Behaviour: Implications for Marketing Strategy. Australia: McGraw-Hill.

Purwanto, M. Ngalim. 2013. Psikologi Pendidikan. Jakarta: PT. Remaja Rosdakarya. Rangkuti, Freddy. 2001. Analisis SWOT Teknik Membedah Kasus Bisnis. Jakarta: Gramedia Pustaka Utama.

Robbins, Stephen P. dan Timothy A. Judge. 2008. Perilaku Organisasi: Organizational Behaviour. Jakarta: Salemba Empat.

Robinson, Richard B. 1997. Manajemen Strategik: Formulasi, Implementasi, dan Pengendalian. Jakarta: Binarupa Aksara. 
Walgito, Bimo. 1990. Pengantar Ilmu Psikologi. Yogyakarta : Andi Offset.

Winardi, J. 2011. Motivasi dan Pemotivasian dalam Manajemen. Jakarta: Rajawali Pers

\section{Profil Penulis}

Pande Putu Indrayana Tirtayasa adalah alumnus Magister Kajian Pariwisata Universitas Udayana. Penulis menyelesaikan studi S1 pada Fakultas Ekonomi Undiknas Denpasar dengan mengambil jurusan Manajemen Keuangan. Penulis pernah bekerja sebagai praktisi di bidang teknologi informasi perhotelan dengan posisi terakhir sebagai IT Manager di Komaneka Resorts, Ubud Bali.

Dr. Ir. Syamsul Alam Paturusi, MSP adalah dosen Prodi Magister Kajian Pariwisata, saat ini menjabat sebagai sekertaris program studi Magister Kajian Pariwisata, Universitas Udayana. Selain itu, beliau juga aktif mengajar sebagai dosen Magister Teknik Arsitektur di Universitas Udayana, Denpasar, Bali. Beliau berasal dari Makassar, Sulawesi Selatan, yang lahir dan dibesarkan di keluarga besar Paturusi. Program pendidikan yang sudah ditempuh yaitu Sarjana (S1) di Arsitektur Universitas Hasanuddin, Makassar, jenjang Magister (S2) di PWK ITB, Bandung, dan jenjang Doktor (S3) di Université de Pau et des Pays de l>Adour, Prancis. 